Research Article

\title{
Experimental and Numerical Vibration Analysis of Hydraulic Pipeline System under Multiexcitations
}

\author{
Peixin Gao $\mathbb{D D}^{1}{ }^{1}$ Hongquan Qu, ${ }^{1}$ Yuanlin Zhang, ${ }^{1}$ Tao Yu $\mathbb{D}^{1},{ }^{1}$ and Jingyu Zhai ${ }^{2}{ }^{2}$ \\ ${ }^{1}$ School of Electromechanical and Automotive Engineering, Yantai University, Yantai 264005, China \\ ${ }^{2}$ School of Mechanical Engineering, Dalian University of Technology, Dalian 116024, China \\ Correspondence should be addressed to Peixin Gao; peigaox@ytu.edu.cn and Tao Yu; yutao@ytu.edu.cn
}

Received 14 July 2019; Revised 10 November 2019; Accepted 30 December 2019; Published 10 March 2020

Academic Editor: Davood Younesian

Copyright (c) 2020 Peixin Gao et al. This is an open access article distributed under the Creative Commons Attribution License, which permits unrestricted use, distribution, and reproduction in any medium, provided the original work is properly cited.

Pipeline systems in aircraft are subjected to both hydraulic pump pressure fluctuations and base excitation from the engine. This can cause fatigue failures due to excessive vibrations. Therefore, it is essential to investigate the vibration behavior of the pipeline system under multiexcitations. In this paper, experiments have been conducted to describe the hydraulic pipeline systems, in which fluid pressure excitation in pipeline is driven by the throttle valve, and the base excitation is produced by the shaker driven by a vibration controller. An improved model which includes fluid motion and base excitation is proposed. A numerical MOCFEM approach which combined the coupling method of characteristics (MOC) and finite element method (FEM) is proposed to solve the equations. The results show that the current MOC-FEM method could predict the vibration characteristics of the pipeline with sufficient accuracy. Moreover, the pipeline under multiexcitations could produce an interesting beat phenomenon, and this dangerous phenomenon is investigated for its consequences from engineering point of view.

\section{Introduction}

The pipeline serving as connections between pump, value, and actuator is one of the most important components in the aircraft hydraulic system. The hydraulic pump with internal fluid pressure fluctuation and the aeroengine with external base excitation result in serious vibration for the hydraulic pipeline system. The excitation frequency range is wide and the interval is narrower. When the fluid pulsation frequencies or the base excitation frequencies are closer to the pipeline natural frequencies, the mechanical resonance would induce and damage the pipeline quickly. Therefore, the accurate descriptions of the hydraulic pipeline system model and the approach for analyzing vibration behavior under multiexcitations to avoid the pipeline resonance are important considerations for the design of hydraulic pipeline in aircraft.

The investigation for the vibration of pipeline and fluid transient has received extensive attention in recent years. The extensive achievements have been investigated on nonlinear stability properties of the pipeline. These studies have reported about the stability of pipeline with sufficient fluid velocity [1-3]. For the hydraulic pipeline system, some reported literature
[4-6] had investigated the fluid fluctuation characteristics by the hydraulic pump. The fluid fluctuation was an inherent characteristic of the hydraulic pump, and the fluid excitation by the pump would induce pipeline vibration. Budny et al. [7] performed the experiment to test the structural pipeline damping, and the results showed that the structural damping could accelerate the fluid transient decay obviously. Edge et al. [8] conducted the test rig to investigate pressure pulsation characteristics in reciprocating pump pipeline system, and the results showed that the pressure pulsation was dependent on the pump speed. Adamkowski et al. [9] conducted a special test rig to test the effect of elastic support onto fluid transients and water hammer. Simão et al. [10] investigated the fluid transients with valve closure suddenly. The test results were consistent with numerical results. In order to validate the fluid model in the laboratory, Mikota et al. [11] conducted the experiment to test the pipeline model. The natural frequency and damping coefficient were obtained in practical fluid pipeline system.

The solution method of fluid equations in the pipeline system was conducted by researchers, such as Wiggert et al. [12], Tijsseling [13], and Lavooij et al. [14]. The method of characteristics which is abbreviated as MOC is always used 
to analyze fluid transients in pipeline systems. An improved MOC approach was proposed by Johnston [15] to investigate the fluid transient characteristics. For the frequency domain solution, the transfer matrix method which is abbreviated as TMM was used to investigate FSI problems of pipelines [16-18]. Based on the finite element method which is abbreviated as FEM, Sreejith et al. [19] investigated the vibration behavior of nuclear pipeline with a sudden valve closure. Gao et al. [20] proposed a reduced order modeling to analyze the vibration characteristics of aero pipeline system. Kochupillai et al. [21] proposed an improved FEM method to investigate the fluid transients with a sudden valve closure. Due to interpolation error, the MOC is not suited to solve the pipeline structural equations. For longdistance pipe with wide frequency range, the TMM approach suffers the instability and error. The FEM approach is suited to solve the structural equations [22]. Recently, the coupling method of characteristics and finite element method which is abbreviated as MOC-FEM approach is proposed to solve the fluid and pipe equations due to high computational accuracy. The fluid equation was solved by MOC approach, and the structural pipeline equation was solved by FEM approach conducted by researchers [23, 24].

From the reviewed works, most of the current methods are excellent to investigate the vibration characteristics of pipe with fluid and the water hammer characteristic under valve closure excitation. However, in practical field, the fluid pressure is the internal excitation and the base excitation by engine is the external excitation. The hydraulic pipeline is suffering serious vibration from the pump fluid fluctuation as well as base excitation by engine. Few works have investigated the pipeline vibration behavior under multiexcitations. Therefore, the experimental and numerical method is essential to recommend for analyzing vibration response characteristics of the pipeline under multiexcitations.

This paper conducts the experiment of hydraulic pipeline under pump and base excitation. The pressure fluctuation is tested by fluid pressure fluctuation sensors. An improved model to predict the vibration response of the pipeline system under multiexcitations is proposed. The coupling MOC-FEM approach combined with the Newmark algorithm method is proposed to solve fluid and pipeline equations. New phenomenon results are illustrated to predict vibration characteristics of the pipeline under multiexcitations.

\section{Experimental Setup}

2.1. The Description of Test Bench. Experiment has been conducted to describe the fluid behavior of the hydraulic pump, as shown schematically in Figure 1. The hydraulic piston pump induces the fluid pressure pulsation with 7 pistons. The converter controls the electric motor with a speed range of 0 to $2000 \mathrm{r} / \mathrm{min}$. The fluid pressure in the hydraulic pipeline is driven by the control of the relief valve and the throttle valve. The base excitation is produced by the shaker driven by an amplified signal from a vibration controller. The base excitation frequency range is $15-2000 \mathrm{~Hz}$ which is investigated based on the aircraft load spectrum, namely, the unbalance harmonic excitation of

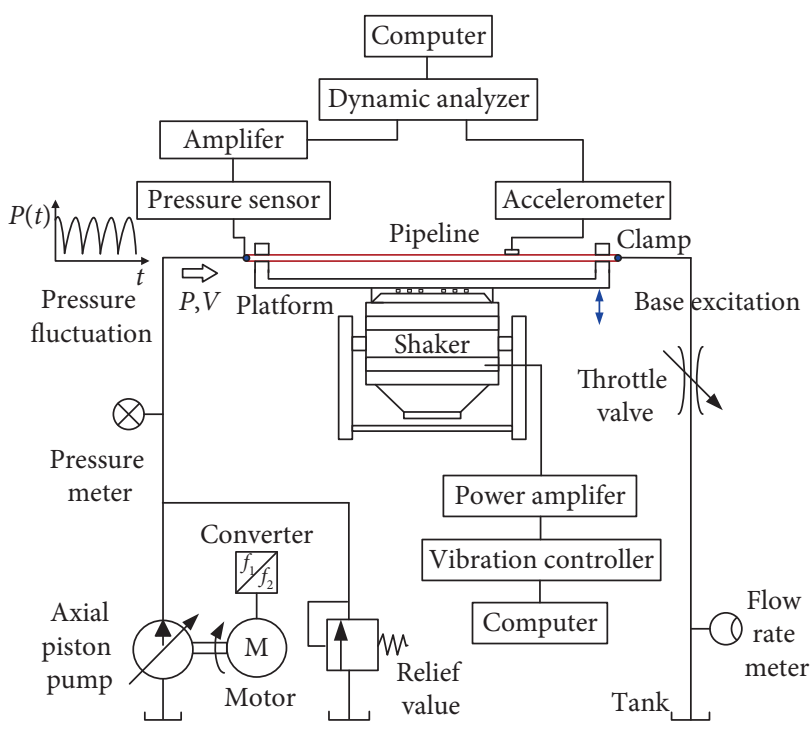

FIgURE 1: Schematic diagram of experimental setup.

aeroengine rotor. The pressure fluctuation sensor is placed at the left of the pipeline with high resolution, and the accelerator, the amplifier, and the signal dynamic analyzer are shown schematically in Figure 2.

The pipeline being tested with two clamps placed at the platform is shown in Figure 3. The boundary conditions for the pipeline are simplified as fixed constraint, and the pressure fluctuation sensor is placed at the left of the pipeline which is the inlet of fluid. The fluid pressure signals are changed with the variable hydraulic pump speed. Table 1 shows the specification of the testing instruments and experimental apparatus.

Table 2 shows the material and geometric details of the pipeline system. A lightweight acceleration sensor to test the vibration signal is placed at $x=300 \mathrm{~mm}$ while the left inlet of the pipeline is set at $x=0$. The signal acquisition is performed by the dynamic analyzers with computer to set the condition and process the vibration signal and analysis.

2.2. The Mechanism of Pressure Fluctuation of Pump. The axial piston pump is mainly composed of the shaft, swashplate, piston, and port plate. The engine drives the main shaft to rotate switching between the oil absorption and the oil outlet of the piston cavity through the valve plate. Due to the existence of swashplate angle, the piston moves back and forth along the centerline of the cavity to realize the oil discharge functions of the pump, as shown in Figure 4 . In the process of pump rotation for one cycle, the fluid pulsation at the pump outlet is produced by the sinusoidal geometric flow pulsation of each piston and the flow filling and flow leakage caused by the transition from the low-pressure chamber to the high-pressure chamber. The instantaneous flow pulsation produced by the axial piston pump is the result of the interaction for several piston fluid pulsations in the oil discharge area. The pressure pulsation of the pipeline system is produced by fluid flow pulsation. 


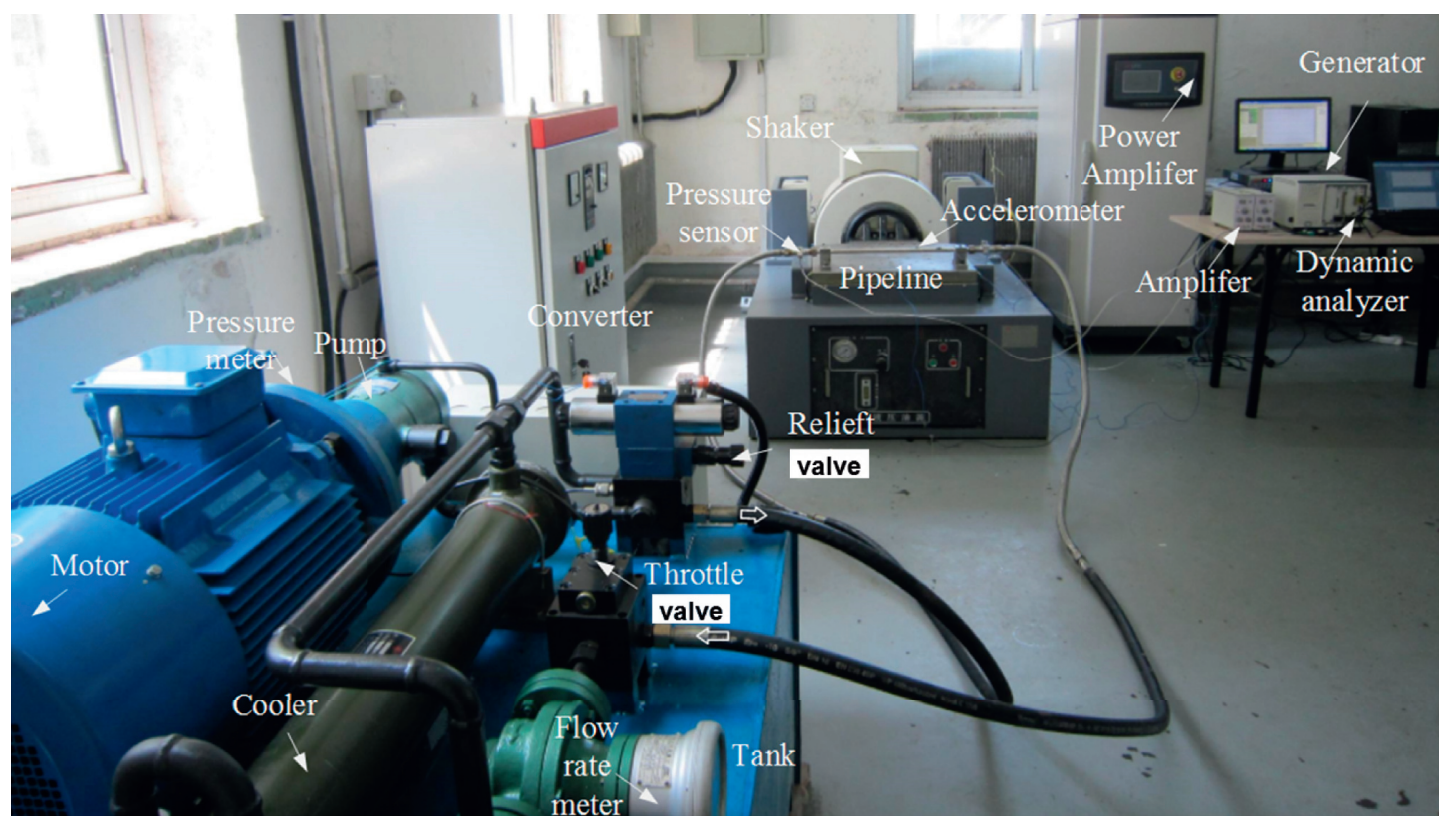

Figure 2: Photograph of test bench layout.

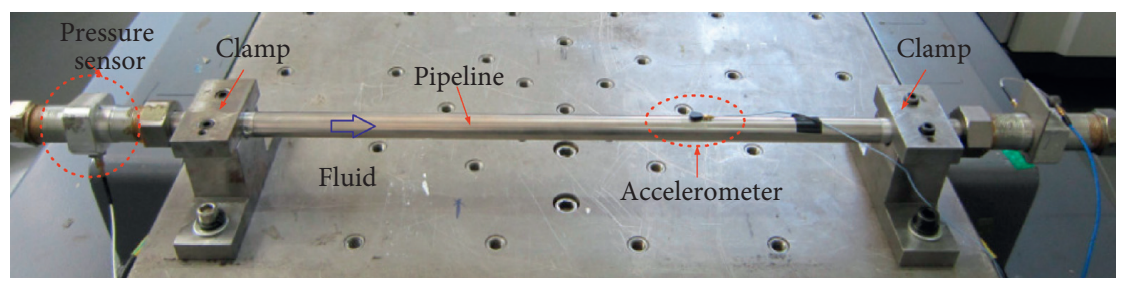

FIgURE 3: Placement of the pressure sensor in the pipeline system.

TABLE 1: The specification of testing instruments and experimental apparatus.

\begin{tabular}{|c|c|c|c|}
\hline System & Item & Description & Remarks \\
\hline \multirow{6}{*}{ Experimental apparatus } & Motor & YX3-180M & Power $18.5 \mathrm{~kW}$ \\
\hline & Pump & MCY14-1B & $\begin{array}{c}\text { Pressure rating } 31.5 \mathrm{MPa} \\
\text { Rotational speed } 0-2000 \mathrm{r} / \mathrm{min}\end{array}$ \\
\hline & Shaker & ES-10G & $\begin{array}{l}\text { Force range } 0-10 \mathrm{kN} \\
\text { Frequency range } 5-5000 \mathrm{~Hz}\end{array}$ \\
\hline & Frequency converter & SD100-4T-18.5 GC & Power $18.5 \mathrm{~kW}$ \\
\hline & Throttle valve & DVP16-1-10B & Pressure range $0-35 \mathrm{MPa}$ \\
\hline & Relief valve & ZDB10VP-1-40B & Pressure range $0-31.5 \mathrm{MPa}$ \\
\hline \multirow{4}{*}{ Measuring instruments } & Accelerometer & PCB-352C22 & $\begin{array}{c}\text { Resolution } 0.004 \mathrm{~g} \\
\text { Frequency range } 1-13000 \mathrm{~Hz}\end{array}$ \\
\hline & Pressure pulsation sensor & CY-YD-205 & $\begin{array}{c}\text { Pressure range } 0-30 \mathrm{MPa} \\
\text { Resolution } 1 \mathrm{~Pa}\end{array}$ \\
\hline & Amplifier & YB5850 & $\begin{array}{c}\text { Gain } 0.01-1000 \mathrm{mV} / \mathrm{pC} \\
\text { Output } \pm 10 \mathrm{~V}\end{array}$ \\
\hline & Dynamic analyzer & NI PXIe-4499 & $\begin{array}{c}16 \text { inputs, } 24 \text { bits, } \\
204.8 \mathrm{kS} / \mathrm{s}\end{array}$ \\
\hline
\end{tabular}

2.3. The Fluid Pressure Characteristics. The pump speed is set at $1800 \mathrm{r} / \mathrm{min}$, the average flow of the pump is $46 \mathrm{~L} / \mathrm{min}$, and the fluid pressure signals tested by pressure sensor are shown in Figure 5. It is obvious that the fluid curve contains harmonics in the frequency domain which are related to pump speed. The harmonics are calculated as follows:

$$
f^{*}=i^{*} \frac{r^{*} n^{*}}{60}
$$

where $n^{*}$ represents the piston number, $r^{*}$ represents the pump speed, and $i^{*}$ represents the frequency numbers.

The fluid pressure curve contains a number of sinusoidal components, the pressure fundamental frequency is $210 \mathrm{~Hz}$, 
TABLE 2: The material and geometric details of the pipeline.

\begin{tabular}{lccc}
\hline Quantities & Symbols & Units & Values \\
\hline Length of the pipeline & $l$ & $\mathrm{~m}$ & 0.5 \\
Outer diameter & $D$ & $\mathrm{~m}$ & 0.18 \\
Density of the pipeline & $\rho_{p}$ & $\mathrm{~kg} / \mathrm{m}^{3}$ & 7850 \\
Elastic modulus & $E$ & $\mathrm{~Pa}$ & $2.06 \times 10^{11}$ \\
Inner diameter & $d$ & $\mathrm{~m}$ & 0.15 \\
Density of fluid & $\rho_{f}$ & - & 860 \\
Poisson ratio & $\lambda$ & $\mathrm{Nm}^{-2}$ & 0.3 \\
Fluid bulk modulus & $K_{f}$ & - & $2.2 \times 10^{9}$ \\
Steady friction factor & $f$ & - & 0.033 \\
Unsteady friction factor & $\gamma$ & Pa.s/m- & 0.0476 \\
Throttle valve load impedance & $Z_{t}$ & $1.43 \times 10^{6}$ \\
\hline
\end{tabular}

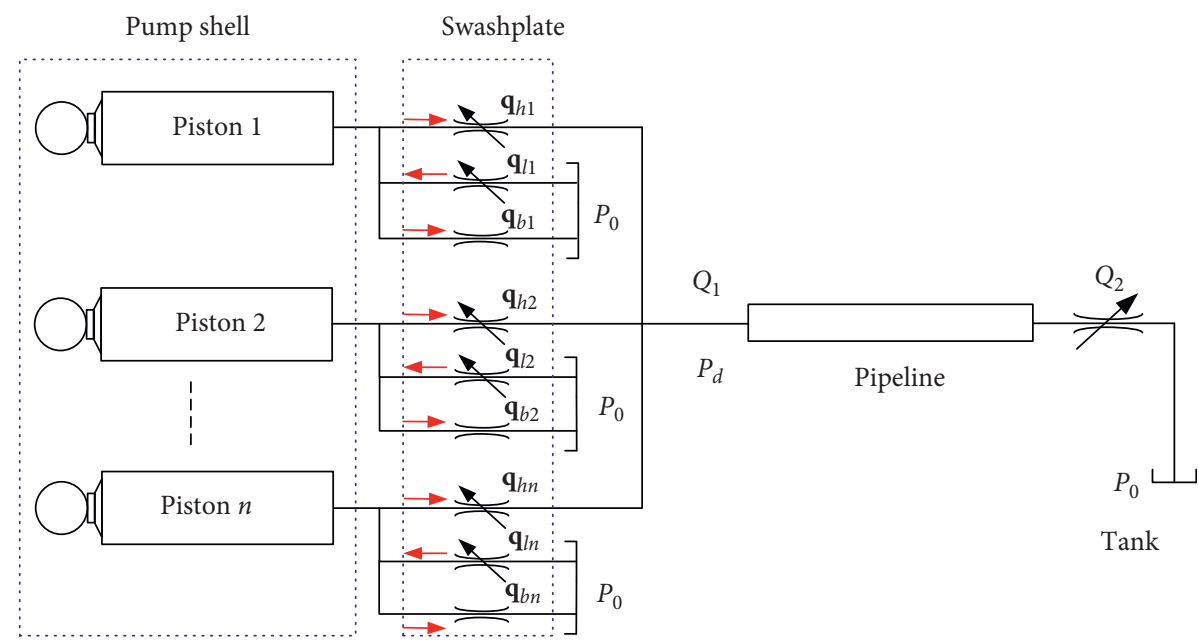

FIgURE 4: The mechanism of pressure fluctuation in the pipeline system.

and it is close to experimental data. The first three harmonics are the main energy. Moreover, some lower harmonics frequencies of $30 \mathrm{~Hz}$ are shown in Figure 5. The reason is related to the pump with 7 pistons and the speed at $1800 \mathrm{r} / \mathrm{min}$; therefore, the fundamental frequency is $30 \mathrm{~Hz}$, and one cycle conveys fluid with each piston, the pump piston contains seven times over each cycle, and the testing fluid pressure curve will be the input of the pipeline modeling.

For the pump speed from $1200 \mathrm{r} / \mathrm{min}$ to $1800 \mathrm{r} / \mathrm{min}$, the average flow of the pump is $30 \mathrm{~L} / \mathrm{min}$ to $46 \mathrm{~L} / \mathrm{min}$. The obtained fluid pressure fluctuation curve is shown in Figure 6. From Figure 6(a), it can be seen that with the increase of pump speed, the pressure fluctuation amplitude increases slightly, and the pressure fluctuation periods are $7.14 \mathrm{~ms}$, $5.71 \mathrm{~ms}$, and $4.76 \mathrm{~ms}$, respectively. It can be seen from Figure 6(b) that the amplitude of the first three harmonics changes significantly, and the harmonics frequency amplitude of the fluid decreases with the increase of harmonics.

\section{Modeling and Numerical Solution}

3.1. The Equations of Fluid and Pipeline. Based on the extended water hammer equation, the governing equation for the continuity of fluid which considers the Poisson coupling and friction coupling is described as follows [13]:

$$
\left(\frac{1}{K_{f}}+\frac{2}{E} \frac{R}{e}\left(1-\lambda^{2}\right)\right) \frac{\partial P}{\partial t}+\frac{\partial V}{\partial x}-2 \lambda \frac{\partial \sigma_{x}}{\partial t}=0
$$

The fluid motion equation in the axial direction can be written as

$$
\frac{\partial P}{\partial x}+\rho_{f} \frac{\partial V}{\partial t}+\frac{2}{R} \tau_{n}=0
$$

where $K_{f} R, \rho_{f}$, and $e$ represent fluid bulk modulus, inner radius of the pipeline, fluid density, and wall thickness, respectively. $P, V, \lambda$, and $E$ are fluid pressure, fluid velocity, Poisson ratio, and Young modulus, respectively. $\dot{u}_{x}$ and $\tau_{n}$ are the pipeline axial stress and the shear stress between fluid and pipeline.

The pipeline motion equation in the axial direction can be described as

$$
\frac{\partial^{2} u_{x}}{\partial t^{2}}-\frac{E}{\rho_{p}} \frac{\partial^{2} u_{x}}{\partial x^{2}}-\frac{\lambda R}{\rho_{p} e} \frac{\partial P}{\partial x}-\frac{2 R}{(2 R+e) e} \tau_{n}=0
$$

where $\rho_{p}$ and $u_{x}$ are the pipeline density and displacement in the axial direction, respectively.

The pipeline motion equation of in lateral direction based on Timoshenko beam theory can be written as 


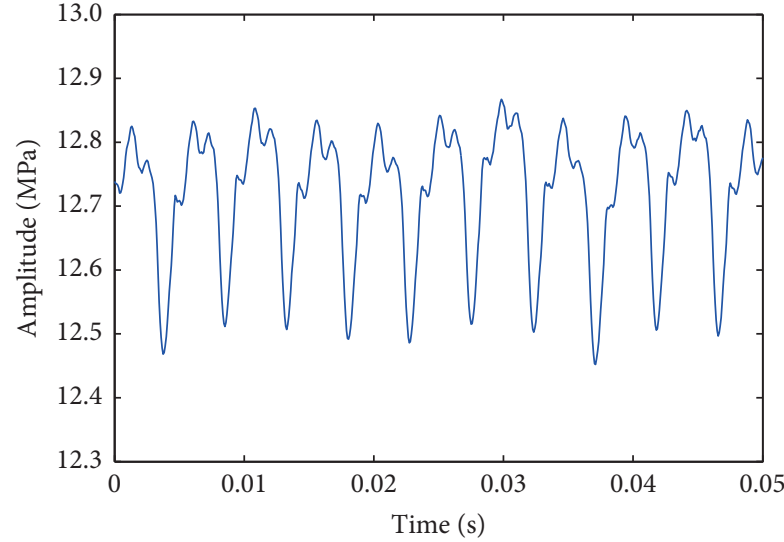

(a)

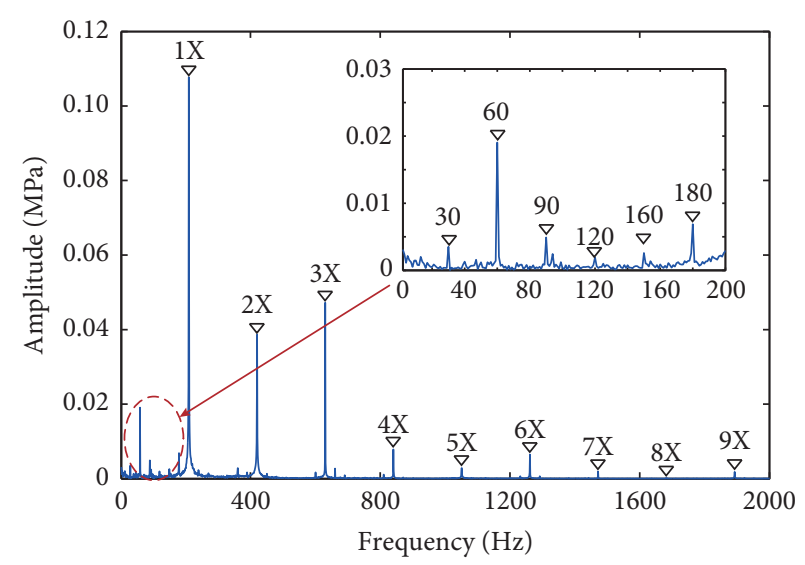

(b)

FIGURE 5: Fluid pressure signals by measurement at $1800 \mathrm{r} / \mathrm{min}$. (a) Fluid pressure signals in time domain and (b) fluid pressure signals in frequency domain.

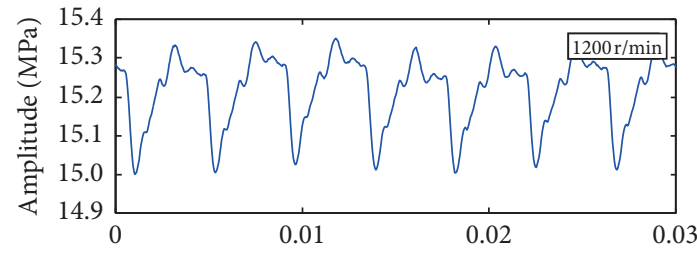

(A)

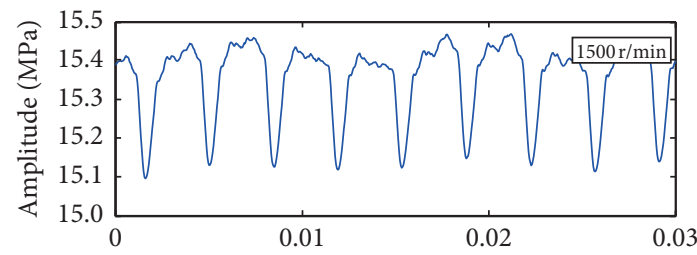

(C)

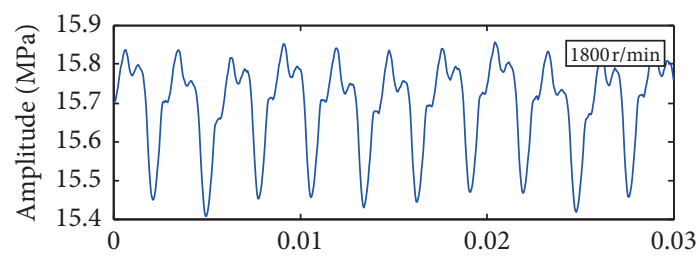

(E)

Time (s)

(a)

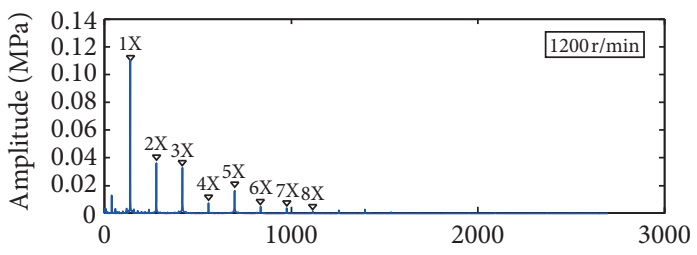

(B)

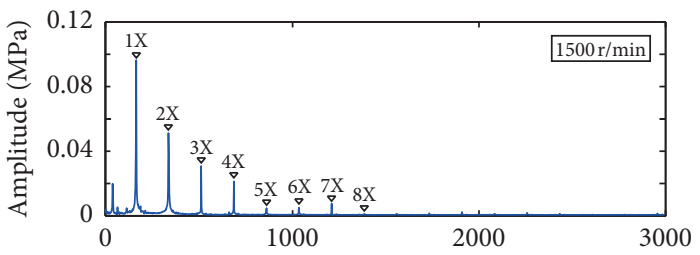

(D)

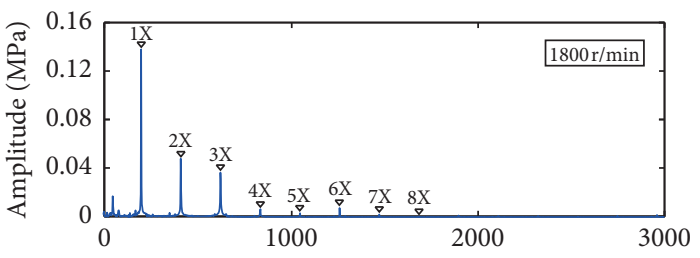

(F)

Frequency $(\mathrm{Hz})$

(b)

FiguRE 6: Measurement of fluid pressure fluctuation under various speeds of the pump. (a) Fluid pressure signals in time domain and (b) fluid pressure signals in frequency domain.

$$
\begin{gathered}
\left(\rho_{f} A_{f}+\rho_{p} A_{p}\right) \frac{\partial^{2} w_{y}}{\partial t^{2}}+E I \frac{\partial^{4} w_{y}}{\partial x^{4}}-\rho_{p} I \frac{\partial^{4} w_{y}}{\partial t^{2} \partial x^{2}}-E I \frac{\rho_{f} A_{f}+\rho_{p} A_{p}}{\kappa^{2} G A_{p}} \frac{\partial^{4} w_{y}}{\partial t^{2} \partial x^{2}}+2 \rho_{f} A_{f} V \frac{\partial w_{y}^{2}}{\partial x \partial t} \\
+\rho_{f} A_{f} V^{2} \frac{\partial w_{y}^{2}}{\partial x^{2}}+\rho_{p} I \frac{\rho_{f} A_{f}+\rho_{p} A_{p}}{\kappa^{2} G A_{p}} \frac{\partial^{4} w_{y}}{\partial t^{4}}=-\left(\rho_{f} A_{f}+\rho_{p} A_{p}\right) \frac{\partial^{2} w_{b}}{\partial t^{2}}-\left(K y-G \frac{\partial w_{y}^{2}}{\partial x^{2}}\right)
\end{gathered}
$$

where $w_{y}$ and $w_{b}$ are the pipeline displacement in the axial direction and base excitation displacement, and it refers to $w_{b}=W_{b} \exp (i \omega t) . A_{f}, A_{p}, I, G, \kappa^{2}, K$, and $G$ are the cross- sectional area of fluid, pipeline, moment of inertia, shear modulus, shear coefficient, support linear stiffness, and shear stiffness, respectively. 
3.2. Numerical Solution. The fluid equations (2) and (3) are solved by MOC approach, and pipeline equations (4) and (5) are solved by FEM approach. The fluid equations (2) and (3) can be described by $\mathrm{C}^{+}$and $\mathrm{C}^{-}$characteristic lines:

$$
\begin{aligned}
& C^{+}:\left\{\begin{array}{l}
\frac{\mathrm{d} P}{\mathrm{~d} t}+c \rho_{f} \frac{\mathrm{d} V}{\mathrm{~d} t}+\frac{2 c}{R} \tau_{n}-2 \lambda c^{2} \rho_{f} \frac{\partial \dot{u}_{x}}{\partial t}=0, \\
\frac{\mathrm{d} x}{\partial t}=+c,
\end{array}\right. \\
& C^{-}:\left\{\begin{array}{l}
\frac{\mathrm{d} P}{\mathrm{~d} t}-c \rho_{f} \frac{\mathrm{d} V}{\mathrm{~d} t}-\frac{2 c}{R} \tau_{n}-2 \lambda c^{2} \rho_{f} \frac{\partial \dot{u}_{x}}{\partial t}=0, \\
\frac{\mathrm{d} x}{\partial t}=-c .
\end{array}\right.
\end{aligned}
$$

$$
V_{L}=V_{E}+\frac{\left(\left(P_{L}-P_{E}\right)-G_{0}\left(f V_{r E}\left|V_{r E}\right|+\delta\left(V_{r L}-V_{r E}\right)\right)+T_{0} \int_{E}^{L}\left(\partial \dot{u}_{x} / \partial t\right) \mathrm{d} t\right)}{Z_{0}} .
$$

The right point fluid velocity which is connected to the throttle valve can be written as

$$
V_{R}=\frac{P_{R}}{Z_{t}}
$$

where $P_{R}$ and $Z_{t}$ are the right point fluid pressure and throttle valve load impedance [25].

The right point fluid pressure and velocity can be described as

$$
\begin{aligned}
P_{R}= & \frac{Z_{t}}{Z_{t}+Z_{0}}\left(P_{F}+Z_{0} V_{F}-G_{0}\left(f V_{r F}\left|V_{r F}\right|+\delta\left(V_{r R}-V_{r F}\right)\right)\right. \\
& \left.+T_{0} \int_{F}^{R} \frac{\partial \dot{u}_{x}}{\partial t} \mathrm{~d} t\right), \\
Q_{R}= & \frac{1}{Z_{T}+Z_{0}}\left(P_{F}+Z_{0} V_{F}-G_{0}\left(f V_{r F}\left|V_{r F}\right|+\delta\left(V_{r R}-V_{r F}\right)\right)\right. \\
& \left.+T_{0} \int_{F}^{R} \frac{\partial \dot{u}_{x}}{\partial t} \mathrm{~d} t\right) .
\end{aligned}
$$

The finite element method is employed to solve the dynamic equations(3) and (4) by weighted residual method. The element equations can be written as

$$
\mathbf{M}^{e} \ddot{\mathbf{x}}+\mathbf{C}^{e} \dot{\mathbf{x}}+\mathbf{K}^{e} \mathbf{x}=\mathbf{F}^{e} .
$$

The stiffness, damping, and mass matrices for fluid and pipeline element can be described as

$$
\left\{\begin{array}{l}
\mathbf{K}^{e}=\mathbf{K}_{\mathrm{fe}}+\mathbf{K}_{\mathrm{pe}} \\
\mathbf{C}^{e}=\mathbf{C}_{\mathrm{fe}}+\mathbf{C}_{\mathrm{pe}} \\
\mathbf{M}^{e}=\mathbf{M}_{\mathrm{fe}}+\mathbf{M}_{\mathrm{pe}}
\end{array}\right.
$$

The equal element $\Delta x$ in pipeline length is described as $\Delta x=L / N$, where $L$ and $N$ are the pipeline length and element number. The time step is described as $\Delta t=\Delta x / c$, where $c$ is the fluid wave speed which refers to $c=1 / \sqrt{\rho_{f}\left(1 / K_{f}+2 R\left(1-\lambda^{2}\right) / E e\right)}$.

The fluid pressure of left point which is connected to the pump has been measured by the fluid pressure sensor, and thus, it can be written as

$$
P_{L}=P_{0}+\sum_{i=1}^{s} P_{i} \sin \left(w_{i} t\right),
$$

where $P_{0}, P_{i} w_{i}$, and $s$ are fluid pressure steady state, the first $i$ order fluid amplitude, fluid frequency, and harmonic number, respectively.

The left point fluid velocity can be written as where $\mathbf{K}_{\mathrm{fe}}, \mathbf{C}_{\mathrm{fe}}$, and $\mathbf{M}_{\mathrm{fe}}$ are the stiffness, damping, and mass matrices of the fluid element. $\mathbf{K}_{\mathrm{pe}}, \mathbf{C}_{\mathrm{pe}}$, and $\mathbf{M}_{\mathrm{pe}}$ are the stiffness, damping, and mass matrices of the pipeline element. The damping of the pipeline is considered Rayleigh damping system, then $\mathbf{C}_{\mathrm{pe}}=\alpha \mathbf{M}_{\mathrm{pe}}+\beta \mathbf{K}_{\mathrm{pe}}$, where $\alpha$ and $\beta$ are the coefficients of Rayleigh damping, respectively.

The shape function and matrix elements of pipeline and fluid are listed in Appendix. The node force matrices can be expressed as

$$
\begin{aligned}
\mathbf{F}^{e}= & \left.\mathbf{N}_{w}(x)^{T}\left(E I w^{\prime \prime \prime}+m_{f} v^{2} w^{\prime}+2 m_{f} v \dot{w}+\rho_{p} I w^{\prime} \dot{w}-E I \frac{\rho_{f} A_{f}}{\kappa^{2} G A_{p}}\right)\right|_{0} ^{l} \\
& +\int_{0}^{l}\left(\frac{2}{R} \tau_{n}+\frac{\lambda R}{\rho_{p} e} \frac{\partial P}{\partial x}\right) \mathbf{U}(x)^{T}+\left.\left(\mathbf{U}(x)^{T} E A_{p} u^{\prime}\right)\right|_{0} ^{l} \\
& +\mathbf{N}_{w}(x)^{T}\left(m_{f}+m_{p}\right) \ddot{w}_{b} .
\end{aligned}
$$

The pipeline system under fluid pressure pulsation and base excitation can be expressed as

$$
\mathbf{M} \ddot{\mathbf{X}}(t)+\mathbf{C} \dot{\mathbf{X}}(t)+\mathbf{K X}(t)=\mathbf{F}(t) .
$$

The solution of the vibration response can be readily carried by Newmark integration method, and the vector and displacement in physical coordinate can be written as

$$
\begin{aligned}
& \dot{\mathbf{X}}_{t+\Delta t}=\dot{\mathbf{X}}_{t}+\left[(1-\delta) \ddot{\mathbf{X}}_{t}+\delta \ddot{\mathbf{X}}_{t+\Delta t}\right] \Delta t \\
& \mathbf{X}_{t+\Delta t}=\mathbf{X}_{t}+\dot{\mathbf{X}}_{t} \Delta t+\left[\left(\frac{1}{2}-\alpha\right) \ddot{\mathbf{X}}_{t}+\alpha \ddot{\mathbf{X}}_{t+\Delta t}\right](\Delta t)^{2},
\end{aligned}
$$

where $\Delta t, \delta$, and $\alpha$ are the time step and the constants, and $\delta \geq 0.5, \alpha \geq 0.25(0.5+\delta)^{2}$.

The motion equation of the pipeline at $t=t+\Delta t$ can be written as 


$$
\mathbf{M} \ddot{\mathbf{X}}_{t+\Delta t}+\mathbf{C} \dot{\mathbf{X}}_{t+\Delta t}+\mathbf{K} \mathbf{X}_{t+\Delta t}=\mathbf{F}_{t+\Delta t} .
$$

Thus, the vibration response at $t+\Delta t$ is obtained by equation (15), equation (16), and equation (17).

\section{Vibration of Pipeline by Pump Fluid Fluctuation}

Experimental and numerical vibration responses of the pipeline under pump fluid pressure fluctuation are investigated comparatively. The pump fluid pressure condition is characterized as reported in Section 2. A comprehensive fluid and pipeline model includes the Poisson and friction coupling, Coriolis and centrifugal forces are proposed, and the coupling MOC-FEM method is adopted in this section.

For the numerical calculation, the pipeline being tested with two clamps placed at the platform is shown in Figure 3. The boundary conditions for the pipeline are simplified as fixed constraint with larger stiffness, and the pipeline is divided by 30 elements equally, and the stiffness value of node 1 and node 31 is set as $1 \times 10^{10} \mathrm{~N} / \mathrm{m}$. The damping ratio of the pipeline is obtained by modal test, here, $\zeta_{1}=0.006$ and $\zeta_{2}=0.009 ; \zeta_{1}$ and $\zeta_{2}$ are corresponding modal damping ratios, and Rayleigh damping coefficient $\alpha=14.903$ and $\beta=$ $0.2415 \times 10^{-5}$ can be calculated by $\alpha=\left(4 \pi f_{1} f_{2}\left(\zeta_{1} f_{2}-\right.\right.$ $\left.\left.\zeta_{2} f_{1}\right)\right) /\left(f_{2}^{2}-f_{1}^{2}\right)$ and $\beta=\left(\zeta_{2} f_{2}-\zeta_{1} f_{1}\right) /\left(\pi\left(f_{2}^{2}-f_{1}^{2}\right)\right)$. The experimental and numerical results for pipeline lateral vibration response are shown comparatively in Figure 7 at a pump speed of $1800 \mathrm{r} / \mathrm{min}$.

From Figure 7, one observes that the experimental and numerical results can match closely. The vibration behavior is complicated by pump fluid excitation. Due to constant water hammer excitation, the first resonance peak occurs obviously in Figure 4(b). Moreover, the pipeline response fundamental frequency is $210 \mathrm{~Hz}$, which is consistent with pump fluid frequency as shown in Figure 3. The second harmonic peak $(420 \mathrm{~Hz})$ is the biggest and the sixth harmonic is the second biggest which are inconsistent with pump harmonics. The reason for this phenomenon is that the first and second pipeline natural frequencies are closer to the fluid second and sixth harmonics. Since the good agreement between the experimental and numerical results, it can validate the coupling MOC-FEM method accurately.

In conclusion, the pipeline vibration amplitude distributes at the closer natural frequencies by pump fluid excitation. Moreover, the pump fluid pressure fluctuation can cause serious pipeline vibration. The mechanical pipeline resonance can occur when fluid harmonics are closer to pipeline natural frequencies.

\section{Superposition of Pump Fluctuation and Base Excitation}

In this section, the pipeline vibration response by the superposition of pump pressure fluctuation and engine base excitation is investigated. The rotational speed of the pump is adjusted to $1660 \mathrm{r} / \mathrm{min}$ at a second frequency of $387 \mathrm{~Hz}$ which is closer to the second pipeline natural frequency. The base excitation frequency is $1043 \mathrm{~Hz}$, which is the second- order resonance frequency of pipeline, and the base excitation acceleration amplitude is $1 g, 2 g$, and $3 g$, respectively. The comparison of pipeline vibration responses obtained by experiment and coupling MOC-FEM approach results under superposition of fluid pressure pulsation and high-order base harmonic excitation is shown in Figure 8.

From Figure 8, the response frequency of the pipeline system at $387 \mathrm{~Hz}$ is produced by pump pressure fluctuation excitation, and the response frequency at $1043 \mathrm{~Hz}$ is caused by base excitation. With the base excitation amplitude being increased from $1 \mathrm{~g}$ to $3 g$, the response amplitude of pipeline at $1043 \mathrm{~Hz}$ increases monotonically, while the response amplitude of pipeline at $387 \mathrm{~Hz}$ decreases slightly. Therefore, the superposition of engine base excitation has a little bit effect on pump fluid pressure fluctuation, and pipeline vibration response at base excitation frequency increases linearly with the increase of the excitation amplitude.

5.1. Beat Phenomenon. When the base excitation frequency is close to the pump pressure fluctuation harmonic frequency, the beat phenomenon in the pipeline system would be induced. The pump speed is adjusted to $1660 \mathrm{r} / \mathrm{min}$. The base excitation frequency is $391 \mathrm{~Hz}$, and the base excitation acceleration amplitude is $0.2 \mathrm{~g}$. The comparison of pipeline vibration response by experiment and coupling MOC-FEM approach under superposition of fluid pressure pulsation and base excitation is shown in Figure 9 .

From Figure 9, one can see that the beat phenomenon occurs due to multiexcitations. The second harmonic pump pressure fluctuation frequency is $387 \mathrm{~Hz}$, and the base excitation frequency is $391 \mathrm{~Hz}$, so it is about 4 "beat" in $1 \mathrm{~s}$. The numerical calculation results could match the measured results closely. Therefore, when the pump fluid pressure frequency is close to the base excitation frequency, the beat vibration phenomenon will be induced, which can result in serious pipeline vibration. In the engineering field, the beat vibration should be avoided for the design of the pipeline system.

5.2. Influence of Exciting Frequency Ratio. In this section, the influence of the exciting frequency ratio $\delta$, which is defined as base excitation frequency and the second harmonic pump pressure fluctuation frequency ratio, on the beat phenomenon is investigated. The rotational speed of the pump remains at $1660 \mathrm{r} / \mathrm{min}$. The base excitation frequencies are $291 \mathrm{~Hz}, 330 \mathrm{~Hz}, 369 \mathrm{~Hz}, 407 \mathrm{~Hz}, 458 \mathrm{~Hz}$, and $485 \mathrm{~Hz}$, respectively; namely, the exciting frequency ratios are 0.75 , $0.85,0.95,1.05,1.18$, and 1.25 , respectively. The variation of the beat vibration according to the frequency ratio in the pipeline system under multiexcitations is shown in Figure 10.

As can be seen from Figure 10, with the increase of exciting frequency ratio, the beat vibration phenomenon of the pipeline system becomes more obvious. When the frequency ratio is greater than 1 , the beat phenomenon of the pipeline decreases gradually. When the exciting frequency is close to 1 (from Figure 11), the beat phenomenon of the pipeline is mostly significant. Therefore, the exciting 


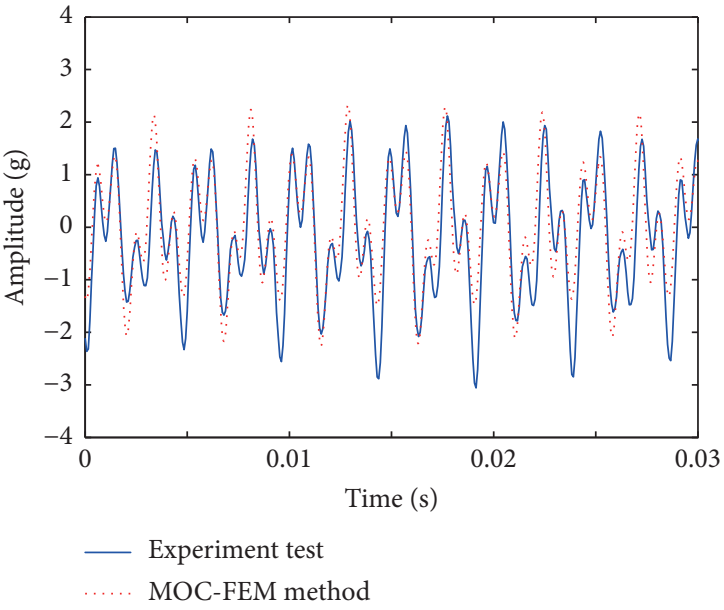

(a)

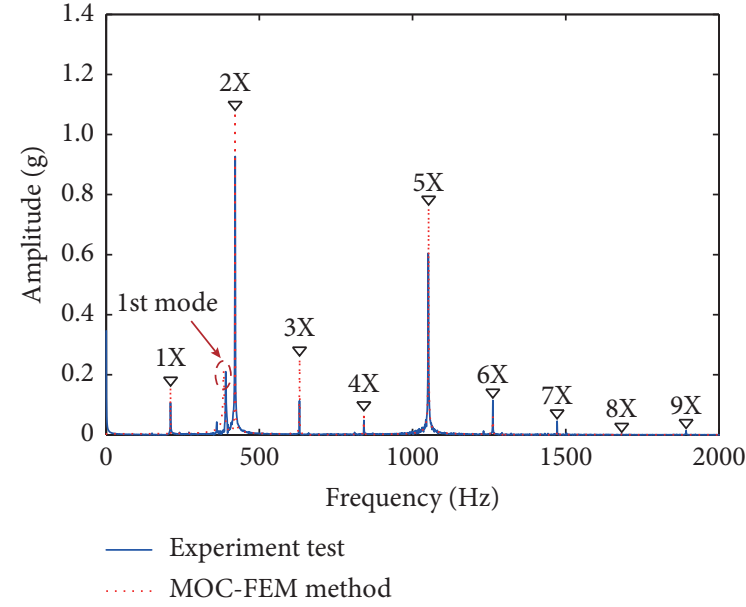

(b)

Figure 7: Pipeline vibration response at a pump speed of $1800 \mathrm{r} / \mathrm{min}$. (a) Vibration response for time domain and (b) pipeline frequency spectrum.

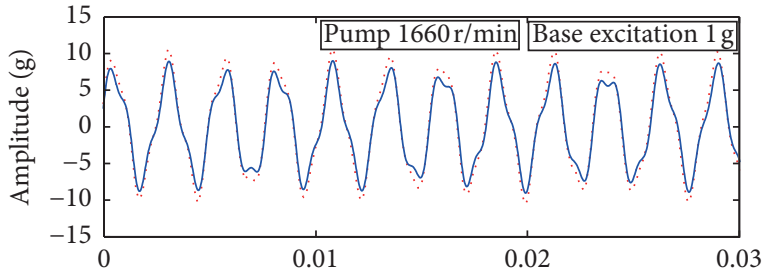

(A)

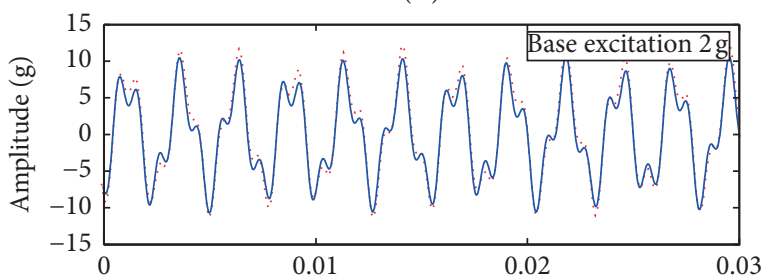

(C)

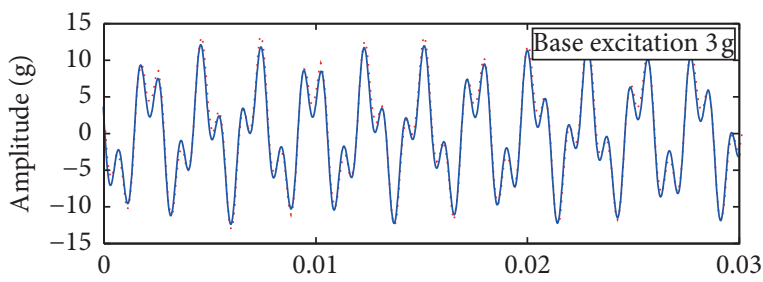

(E)

Time (s)

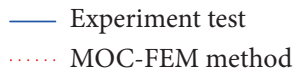

(a)

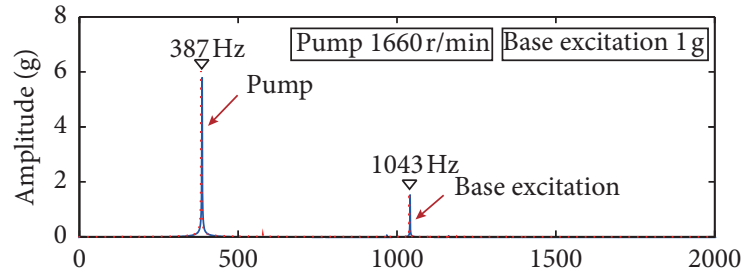

(B)

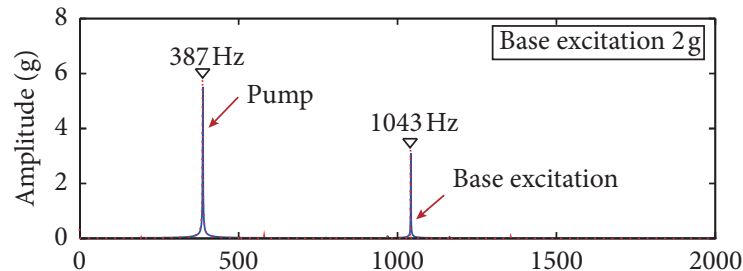

(D)

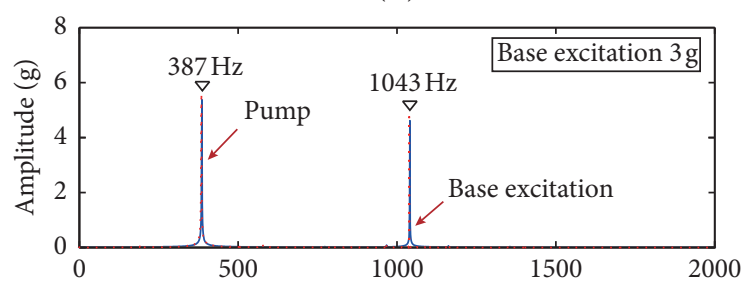

(F)

Frequency $(\mathrm{Hz})$

(b)

Figure 8: Pipeline vibration response under the superposition of fluid pressure pulsation and high-order base harmonic excitation. (a) Vibration response for time domain and (b) pipeline frequency spectrum.

frequency ratio $\delta$ has a remarkable effect on the beat phenomenon, and the obvious beat phenomenon can be obtained with the frequency ratio range $[0.85 \sim 1.18]$ in the hydraulic pipeline system.
5.3. Vibration of Pipeline under Variable Multiexcitations. This section studies the vibration response characteristics of the pipeline system under the pump sweep excitation and the base sweep excitation. The speed of the pump increases 


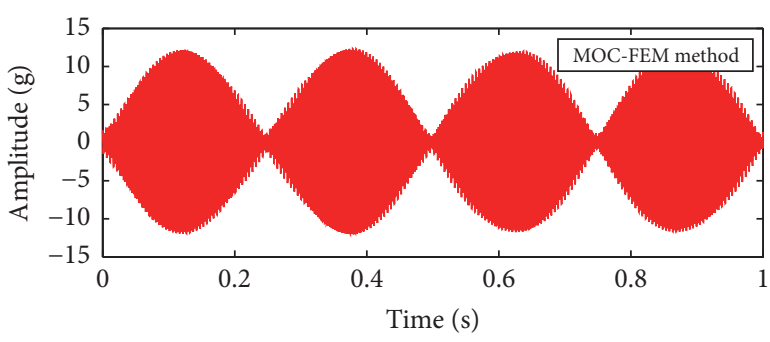

(a)

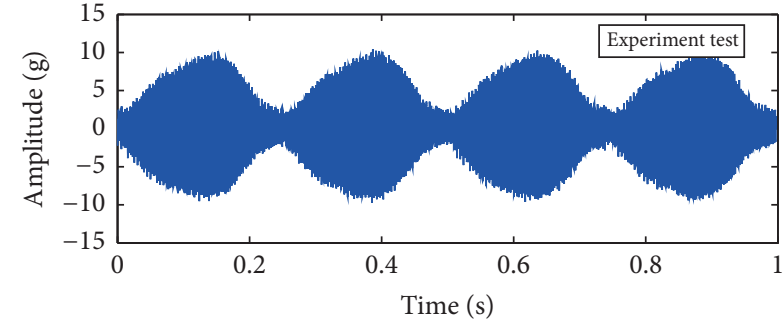

(b)

Figure 9: Pipeline vibration response under multiexcitations.
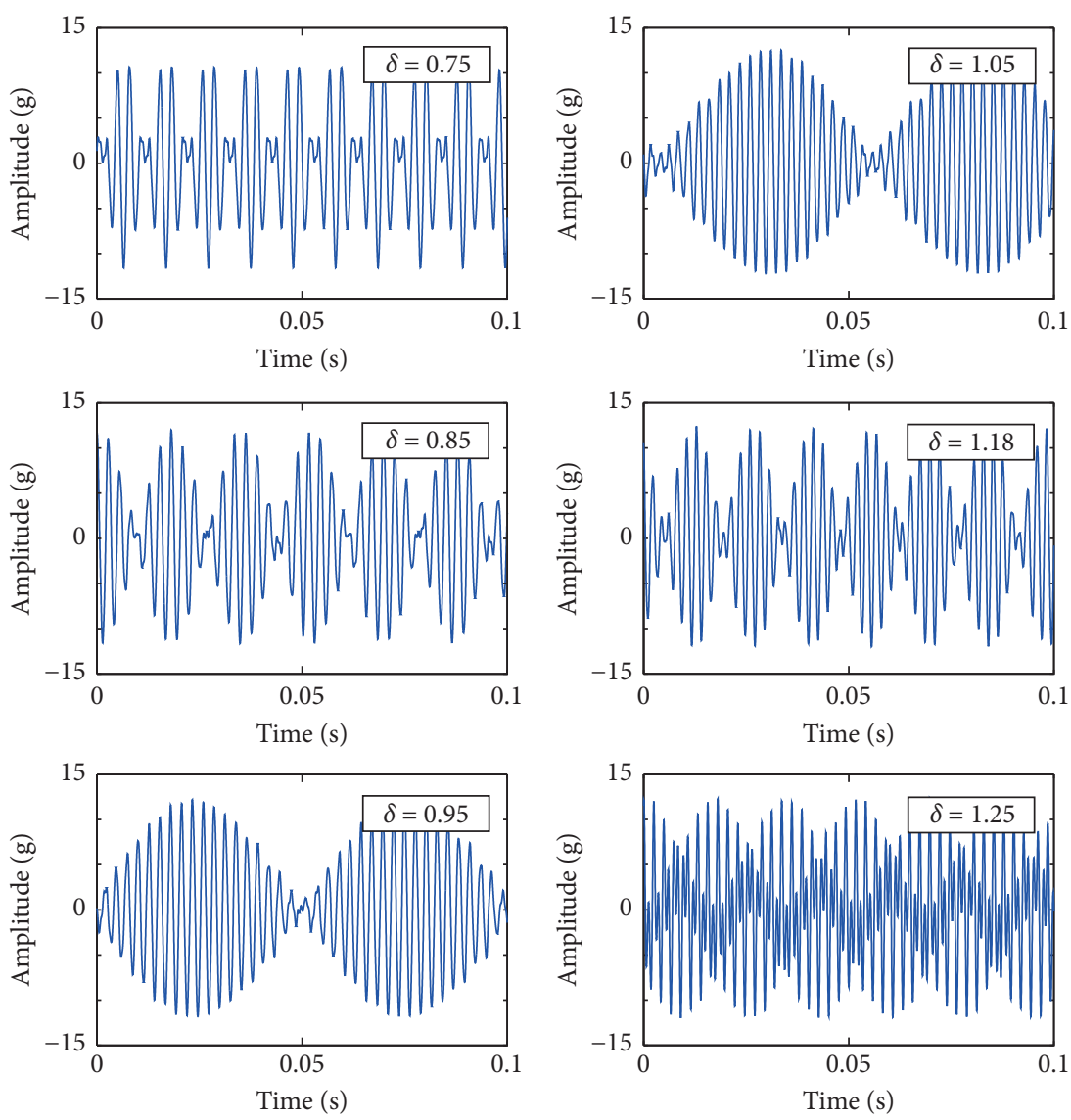

FIgURE 10: Variation of the beat vibration according to frequency ratio.

from 850 to $2000 \mathrm{r} / \mathrm{min}$ firstly, and then, it decreases to $1250 \mathrm{r} / \mathrm{min}$. The frequency range of base excitation is $250-1200 \mathrm{~Hz}$, and the base excitation amplitude is $0.4 \mathrm{~g}$. During the test, the shaker is adjusted to increase the excitation frequency linearly, and the frequency converter is adjusted to increase the speed of the pump at time $t=0-40 \mathrm{~s}$ and decrease at time $t=40-120 \mathrm{~s}$. Three-dimensional waterfall of dynamic response under the superposition of variable pressure pulsation frequency and variable base excitation frequency is shown in Figure 11.

From Figure 11, one can see that the high-order harmonics of the pump source fluid pressure pulsation causes resonance peaks at $388 \mathrm{~Hz}$ (the first-order nature frequency of the pipeline) and $1043 \mathrm{~Hz}$ (the second-order nature frequency) of the pipeline during the increasing speed of the pump. When $t=21 \mathrm{~s}$, the second fluid harmonic frequency reaches $388 \mathrm{~Hz}$, and the pump excitation frequency and the base excitation frequency are close to the natural frequency of the pipeline system, resulting in a large resonance amplitude of the pipeline system. When $t=40 \mathrm{~s}$, the speed of the pump reaches $2000 \mathrm{r} / \mathrm{min}$ and then decreases to $1250 \mathrm{r} / \mathrm{min}$, and the base excitation frequency continues to increase. When $t=68 \mathrm{~s}$, the pipeline system has a large resonance peak at $388 \mathrm{~Hz}$. The reason is that the second-order harmonic frequency of fluid pressure pulsation is close to the firstorder natural frequency of the pipeline system. In the 


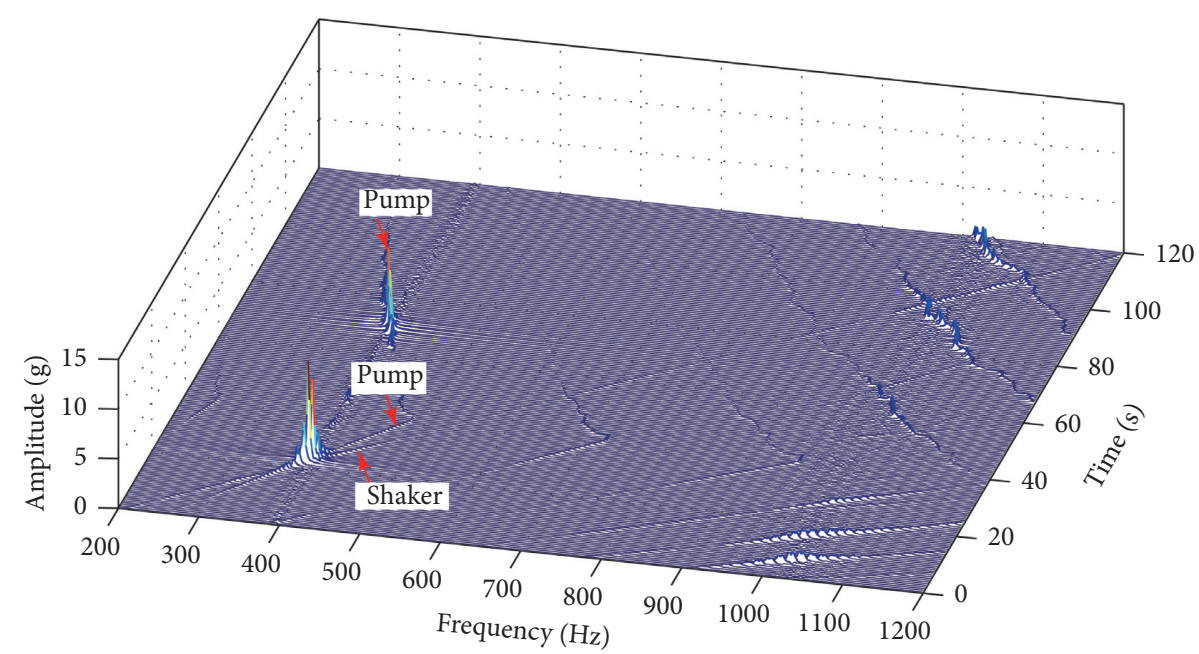

Figure 11: Three-dimensional waterfall of dynamic response under the superposition of variable pressure pulsation frequency and variable base excitation frequency.

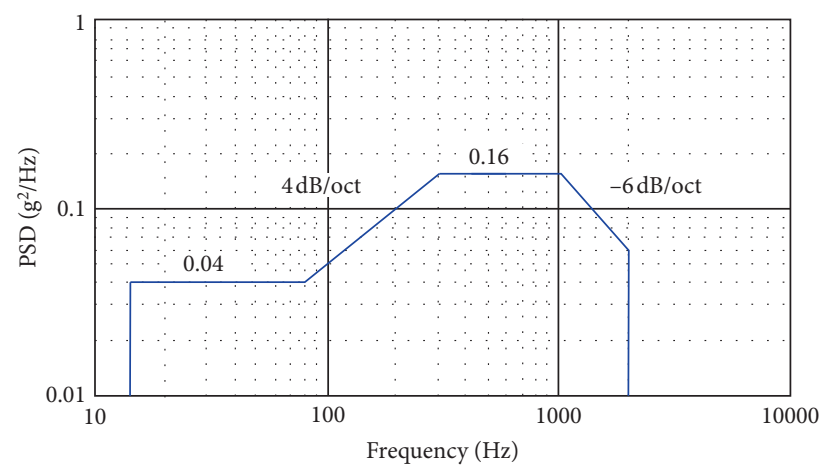

FIGURE 12: Random load spectrum of pipeline in aircraft.

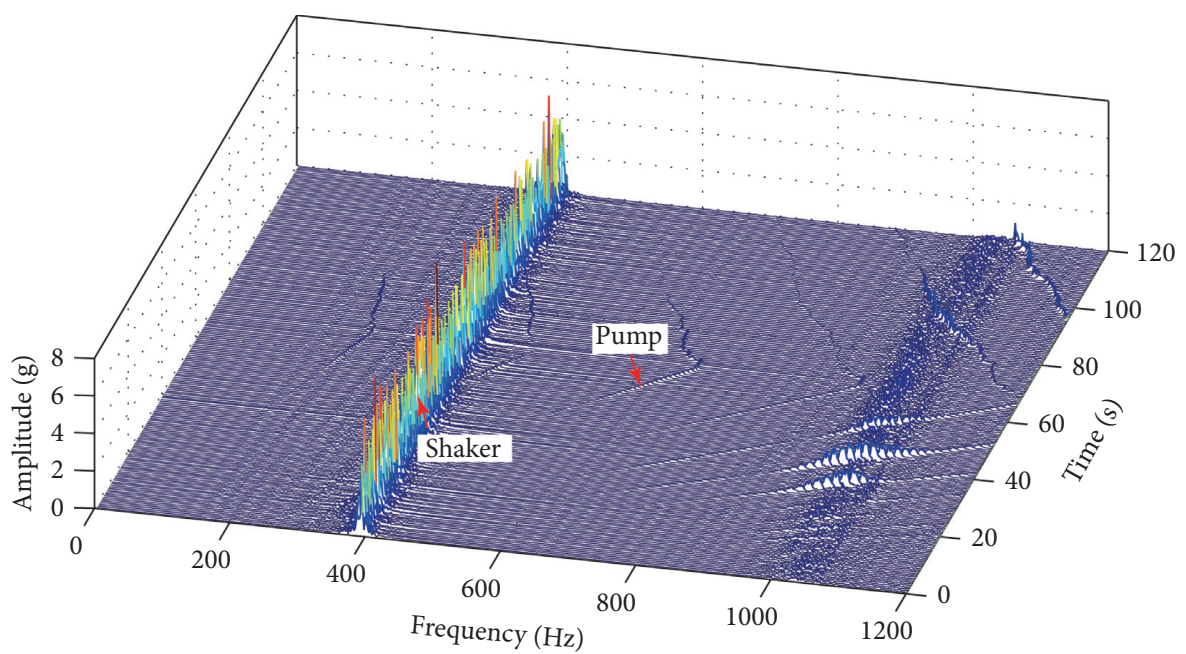

FIgURE 13: Three-dimensional waterfall of vibration response under pump pressure pulsation frequency and base random excitation.

process of increasing the base excitation frequency, there are many resonance peaks in the pipeline system at $1043 \mathrm{~Hz}$ (the second bending frequency of the pipeline system).
5.4. Vibration of Pipeline under Random Excitation. This section studies the vibration response of the hydraulic pipeline under the base random excitation. The environment 
of the aircraft is random vibration with wide frequency range, the hydraulic pipeline system is subject to random excitation of the aircraft body, and its load spectrum is shown in Figure 12. The speed range of the pump is $0-1800 \mathrm{r} / \mathrm{min}$. The vibration responses of the pipeline under pump pressure pulsation excitation and base random excitation are shown in Figure 13.

It can be seen from Figure 13 that with the increase of the speed of the pump, the high-order harmonic frequency of the fluid causes the resonance peaks of the pipeline firstly. When the second harmonic frequency of the fluid reaches $388 \mathrm{~Hz}$, it causes serious vibration due to mechanical resonance. With the speed of the pump increasing continuously, the vibration response of the pipeline decreases rapidly. From Figure 13, the vibration response frequency of the pipeline under the base random excitation is mainly around $388 \mathrm{~Hz}$, which is closer to the first-order bending natural frequency of the pipeline. Another peak value occurs between 1000 and $1100 \mathrm{~Hz}$, which is the second-order natural frequency of the pipeline.

The above discussion is quite meaningful that the pipeline has multiresonances under pump fluid pressure pulsation and base excitation; the beat phenomenon will occur when pump fluid pressure pulsation frequency is closer to the base excitation frequency. The large displacement of the pipeline can damage pipeline through overload and fatigue easily. Therefore, the hydraulic pipeline system should be considered to avoid the beat phenomenon or mechanical resonance, and the exciting frequency ratio should be kept away from this dangerous range in aircraft.

\section{Conclusions}

In the present paper, the experiments are conducted to investigate the vibration characteristics of the pipeline with multiexcitations. The coupling MOC-FEM method for analyzing the vibration responses of pipeline under pump pressure fluctuation and engine base excitation is described. New results are obtained.

The fluid pressure curve contains a number of sinusoidal components by the hydraulic pump, and the first three harmonics are the main energy. The pipeline vibration amplitude distributes at the closer natural frequencies by pump fluid excitation. Moreover, the pump fluid pressure fluctuation can cause serious pipeline vibration. The mechanical resonance can occur when fluid harmonics are closer to pipeline natural frequencies.

The superposition of engine base excitation has a little bit effect on pump fluid pressure fluctuation, and pipeline vibration response at the base excitation frequency increases linearly with the increase of the excitation amplitude. The beat phenomenon will occur when fluid pulsation frequency is closer to the base excitation frequency. The hydraulic pipeline should be considered to avoid beat phenomenon or mechanical resonance, and the exciting frequency ratio should be kept away from this dangerous range [0.85 1.18].

For analyzing the vibration behavior of the pipeline under the pump fluid pressure and engine base excitation, the coupling MOC-FEM method exhibits high accuracy, which may serve as an important consideration for the design of hydraulic pipeline in aircraft.

\section{Appendix}

The pipeline element is described as Timoshenko beam element with two nodes in this paper. Each node has three degrees of freedom (DOF) which represents transverse displacement $(w)$, cross section rotation $(\theta)$, and axial displacement $(u)$. The local nodal displacements are given by

$$
\left\{\mathbf{q}^{e}\right\}=\left[w_{i}, \theta_{i}, u_{i}, w_{j}, \theta_{j}, u_{j}\right]^{T} .
$$

The nodal displacements by finite element shape functions can be written as

$$
\left\{\begin{array}{l}
w(x) \\
\theta(x) \\
u(x)
\end{array}\right\}=\left[\begin{array}{c}
\mathbf{N}_{w}(x) \\
\mathbf{N}_{\theta}(x) \\
\mathbf{U}(x)
\end{array}\right]\left\{\mathbf{q}^{e}\right\},
$$

where the shape functions can be expressed as

$$
\begin{aligned}
\mathbf{N}_{w}(x) & =\left[\begin{array}{llllll}
N_{1} & N_{2} & 0 & N_{3} & N_{4} & 0
\end{array}\right], \\
\mathbf{N}_{\theta}(x) & =\left[\begin{array}{llllll}
\bar{N}_{1} & \bar{N}_{2} & 0 & \bar{N}_{3} & \bar{N}_{4} & 0
\end{array}\right], \\
\mathbf{U}(x) & =\left[\begin{array}{llllll}
0 & 0 & U_{1} & 0 & 0 & U_{2}
\end{array}\right],
\end{aligned}
$$

in which

$$
\begin{aligned}
& N_{1}=1-\frac{1}{l\left(l^{2}+12 \psi\right)}\left(12 \psi x+3 l x^{2}-2 x^{3}\right), \\
& N_{2}=\frac{1}{l\left(l^{2}+12 \psi\right)}\left(\left(l^{2}+6 \psi\right) l x-\left(2 l^{2}+6 \psi\right) x^{2}-l x^{3}\right), \\
& N_{3}=\frac{1}{l\left(l^{2}+12 \psi\right)}\left(12 \psi x+3 l x^{2}-2 x^{3}\right), \\
& N_{4}=\frac{1}{l\left(l^{2}+12 \psi\right)}\left(-6 \psi l x+\left(6 \psi-l^{2}\right) x^{2}+l x^{3}\right), \\
& \bar{N}_{1}=\frac{1}{l\left(l^{2}+12 \psi\right)}\left(6 x^{2}-6 \psi x\right), \\
& \bar{N}_{2}=\frac{1}{l\left(l^{2}+12 \psi\right)}\left(l^{3}+12 \psi l-\left(4 l^{2}+12 \psi\right)+3 l x^{2}\right), \\
& \bar{N}_{3}=\frac{1}{l\left(l^{2}+12 \psi\right)}\left(6 l x-6 x^{2}\right), \\
& \bar{N}_{4}=\frac{1}{l\left(l^{2}+12 \psi\right)}\left(3 l x^{2}-\left(2 l^{2}-12 \psi\right) x\right), \\
& U_{1}=1-\frac{x}{l}, \\
& U_{2}=\frac{x}{l},
\end{aligned}
$$

where $l$ is the beam element length, $\psi=E I / \kappa^{2} G A_{p}$. 
The stiffness matrix of pipeline element can be written as

$$
\begin{aligned}
\mathbf{K}_{\mathrm{pe}}= & E I \int_{0}^{l} \mathbf{N}_{\theta}(x)_{x}^{T} \mathbf{N}_{\theta}(x)_{x} \mathrm{~d} x+E A_{p} \int_{0}^{l} \mathbf{U}(x)_{x}^{T} \mathbf{U}(x)_{x} \mathrm{~d} x \\
& +\kappa^{2} G A_{p} \int_{0}^{l}\left(\mathbf{N}_{w}(x)_{x}^{T}-\mathbf{N}_{\theta}(x)^{T}\right)\left(\mathbf{N}_{w}(x)_{x}-\mathbf{N}_{\theta}(x)\right) \mathrm{d} x .
\end{aligned}
$$

The mass matrix of pipeline element can be expressed as

$$
\begin{aligned}
\mathbf{M}_{\mathrm{pe}}= & m_{p} \int_{0}^{l} \mathbf{N}_{w}(x)^{T} \mathbf{N}_{w}(x) \mathrm{d} x+m_{p} \int_{0}^{l} \mathbf{U}(x)^{T} \mathbf{U}(x) \mathrm{d} x \\
& +\rho_{p} I \int_{0}^{l} \mathbf{N}_{\theta}(x)^{T} \mathbf{N}_{\theta}(x) \mathrm{d} x .
\end{aligned}
$$

The stiffness, damping, and mass matrices of the fluid element can be written as

$$
\begin{aligned}
\mathbf{K}_{\mathrm{fe}}= & -m_{f} v^{2} \int_{0}^{l} \mathbf{N}_{w}(x)_{x}^{T} \mathbf{N}_{w}(x)_{x} \mathrm{~d} x, \\
\mathbf{C}_{\mathrm{fe}}= & m_{f} v \int_{0}^{l}\left[\mathbf{N}_{w}(x)^{T} \mathbf{N}_{w}(x)_{x}-\mathbf{N}_{w}(x)_{x}^{T} \mathbf{N}_{w}(x)_{x}\right] \mathrm{d} x, \\
\mathbf{M}_{\mathrm{fe}}= & m_{f} \int_{0}^{l} \mathbf{N}_{w}(x)^{T} \mathbf{N}_{w}(x) \mathrm{d} x+m_{f} \int_{0}^{l_{0}} \mathbf{U}(x)^{T} \mathbf{U}(x) \mathrm{d} x \\
& +\rho_{p} I_{p} \int_{0}^{l} \mathbf{N}_{\theta}(x)^{T} \mathbf{N}_{\theta}(x) \mathrm{d} x .
\end{aligned}
$$

\section{Data Availability}

The data used to support the findings of this study are available from the corresponding author upon request.

\section{Conflicts of Interest}

The authors declare that they have no conflicts of interest.

\section{Acknowledgments}

This work was supported by the National Natural Science Foundation of China (Grant no. 51805462) and Natural Science Foundation of Shandong Province (Grant no. ZR2018MEE021).

\section{References}

[1] M. P. Paidoussis and G. X. Li, "Pipes conveying fluid: a model dynamical problem," Journal of Fluids and Structures, vol. 7, no. 2, pp. 137-204, 1993.

[2] M. P. Paidoussis, Fluid-tructure Interactions: Slender Structures and Axial Flow, vol. 1, Elsevier Academic Press, London, UK, 1998.

[3] M. P. Paidoussis, Fluid-tructure Interactions: Slender Structures and Axial Flow, vol. 2, Elsevier Academic Press, London, UK, 2004.

[4] M. K. Bahr, J. Svoboda, and R. B. Bhat, "Vibration analysis of constant power regulated swash plate axial piston pumps," Journal of Sound and Vibration, vol. 259, no. 5, pp. 1225-1236, 2003.
[5] D. N. Johnston and J. E. Drew, "Measurement of positive displacement pump flow ripple and impedance," Proceedings of the Institution of Mechanical Engineers, Part I: Journal of Systems and Control Engineering, vol. 210, no. 1, pp. 65-74, 1996.

[6] C. Guan, Z. Jiao, and S. He, "Theoretical study of flow ripple for an aviation axial-piston pump with damping holes in the valve plate," Chinese Journal of Aeronautics, vol. 27, no. 1, pp. 169-181, 2014.

[7] D. D. Budny, F. J. Hatfield, and D. C. Wiggert, "An experimental study on the influence of structural damping on internal fluid pressure during a transient flow," Journal of Pressure Vessel Technology, vol. 112, no. 3, pp. 284-290, 1990.

[8] K. A. Edge, O. P. Boston, K. C. S. Xiao, K. C. M. J. Longvill, and K. C. C. R. Burrows, "Pressure pulsations in reciprocating pump piping systems part 2: experimental investigations and model validation," Proceedings of the Institution of Mechanical Engineers, Part I: Journal of Systems and Control Engineering, vol. 211, no. 3, pp. 239-250, 1997.

[9] A. Adamkowski, S. Henclik, W. Janicki, and M. Lewandowski, "The influence of pipeline supports stiffness onto the water hammer run," European Journal of Mechanics - B/Fluids, vol. 61, pp. 297-303, 2017.

[10] M. Simão, J. Mora-Rodriguez, and H. Ramos, "Mechanical interaction in pressurized pipe systems: experiments and numerical models," Water, vol. 7, no. 11, pp. 6321-6350, 2015.

[11] G. Mikota, B. Manhartsgruber, H. Kogler, and F. Hammerle, "Modal testing of hydraulic pipeline systems," Journal of Sound and Vibration, vol. 409, pp. 256-273, 2017.

[12] D. C. Wiggert, F. J. Hatfield, and S. Stuckenbruck, "Analysis of liquid and structural transients in piping by the method of characteristics," Journal of Fluids Engineering, vol. 109, no. 2, pp. 161-165, 1987.

[13] A. S. Tijsseling, "Fluid-structure interaction in liquid-filled pipe systems: a review," Journal of Fluids and Structures, vol. 10, no. 2, pp. 109-146, 1996.

[14] C. S. W. Lavooij and A. S. Tusseling, "Fluid-structure interaction in liquid-filled piping systems," Journal of Fluids and Structures, vol. 5, no. 5, pp. 573-595, 1991.

[15] D. N. Johnston, "Efficient methods for numerical modeling of laminar friction in fluid lines," Journal of Dynamic Systems, Measurement, and Control, vol. 128, no. 4, pp. 829-834, 2006.

[16] Q. S. Li, K. Yang, L. Zhang, and N. Zhang, "Frequency domain analysis of fluid-structure interaction in liquid-filled pipe systems by transfer matrix method," International Journal of Mechanical Sciences, vol. 44, no. 10, pp. 2067-2087, 2002.

[17] T. A. El-Sayed and H. H. El-Mongy, "Free vibration and stability analysis of a multi-span pipe conveying fluid using exact and variational iteration methods combined with transfer matrix method," Applied Mathematical Modelling, vol. 71, pp. 173-193, 2019.

[18] A. Batura, A. Novikov, A. Pashchenko, and Y. Dubyk, "An application of the transfer matrix approach for a dynamic analysis of complex spatial pipelines," Nuclear Engineering and Design, vol. 349, pp. 174-182, 2019.

[19] B. Sreejith, K. Jayaraj, N. Ganesan, C. Padmanabhan, P. Chellapandi, and P. Selvaraj, "Finite element analysis of fluid-structure interaction in pipeline systems," Nuclear Engineering and Design, vol. 227, no. 3, pp. 313-322, 2004.

[20] P.-X. Gao, J.-Y. Zhai, Y.-Y. Yan, Q.-K. Han, F.-Z. Qu, and X.-H. Chen, "A model reduction approach for the vibration analysis of hydraulic pipeline system in aircraft," Aerospace Science and Technology, vol. 49, pp. 144-153, 2016. 
[21] J. Kochupillai, N. Ganesan, and C. Padmanabhan, "A new finite element formulation based on the velocity of flow for water hammer problems," International Journal of Pressure Vessels and Piping, vol. 82, no. 1, pp. 1-14, 2005.

[22] S. Henclik, "A numerical approach to the standard model of water hammer with fluid-structure interaction," Journal of Theoretical and Applied Mechanics, vol. 53, no. 3, pp. 543-555, 2015.

[23] A. Ahmadi and A. Keramat, "Investigation of fluid-structure interaction with various types of junction coupling," Journal of Fluids and Structures, vol. 26, no. 7-8, pp. 1123-1141, 2010.

[24] R. Zanganeh, A. Ahmadi, and A. Keramat, "Fluid-structure interaction with viscoelastic supports during waterhammer in a pipeline," Journal of Fluids and Structures, vol. 54, pp. 215-234, 2015.

[25] D. N. Johnston and K. A. Edge, "The impedance characteristics of fluid power components: restrictor and flow control valves," Proceedings of the Institution of Mechanical Engineers, Part I: Journal of Systems and Control Engineering, vol. 205, no. 1, pp. 3-10, 1991. 